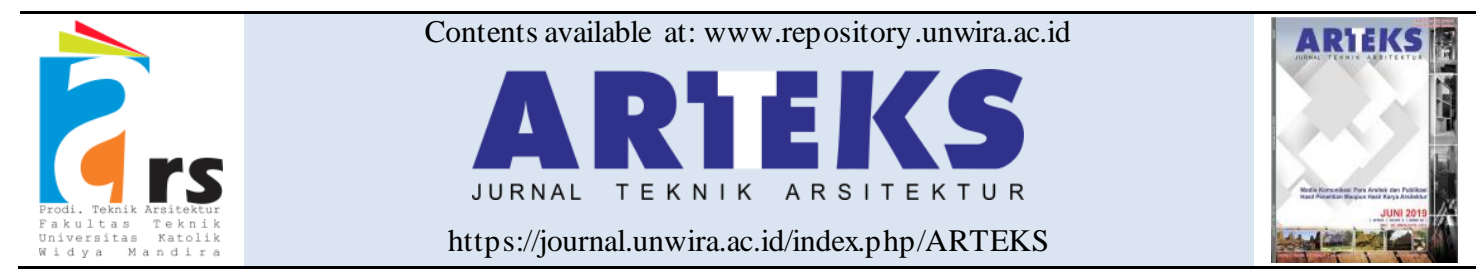

Research paper

doi: 10.30822/arteks.v6i1.569

\title{
The comparison of device materials of sliding sudare using a prototyping method
}

\author{
Agus Hariyadi* ${ }^{\mathbb{D}}$, Esti Setyaning Jati ${ }^{\mathbb{D}}$, Nabila Afif ${ }^{\mathbb{D}}$, Alya F. Taufiqoh \\ Department of Architecture and Planning, Faculty of Engineering, \\ Universitas Gadjah Mada, Jl. Grafika 2 Kampus UGM, Yogyakarta Indonesia
}

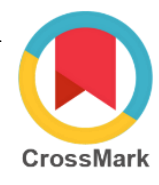

\begin{tabular}{|c|c|}
\hline ARTICLE INFO & ABSTRACT \\
\hline $\begin{array}{l}\text { Article history: } \\
\text { Received July } 15,2020 \\
\text { Received in revised form August 13, } \\
2020 \\
\text { Accepted October } 11,2020 \\
\text { Available online April } 01,2021 \\
\end{array}$ & $\begin{array}{l}\text { Sliding Sudare has a big potential to be developed considered its } \\
\text { high effectiveness in minimizing building energy consumption while } \\
\text { still maintaining its visibility quality. Meanwhile, its original blinds } \\
\text { that is made of bamboo cannot withstand extreme weather and have } \\
\text { a short lifespan. Therefore, this research is to investigate the } \\
\text { effectiveness of the other material alternatives namely stainless }\end{array}$ \\
\hline $\begin{array}{l}\text { *Corresponding author: Agus Hariyadi } \\
\text { Department of Architecture and Planning, } \\
\text { Faculty of Engineering, Universitas Gadjah } \\
\text { Madar, Indonesia } \\
\text { Email: agus@ugm.ac.id } \\
\text { ORCID: https://orcid.org/0000-0003-3617- } \\
\text { 3790 }\end{array}$ & $\begin{array}{l}\text { steel, plastic, and natural fiber. A scaled model is used for } \\
\text { prototyping the materials in the shape of bicycle spokes, PLA+ }(3 D \\
\text { printer filament), and bamboo slats as the blinds. These everyday } \\
\text { objects were tested in terms of their physical characteristic and were } \\
\text { measured by four parameters (security requirement, weather } \\
\text { resistance, construction process, and cost-effectiveness). From the } \\
\text { research, it was concluded that bicycle spokes has the highest } \\
\text { overall performance with the highest advantages in weather } \\
\text { resistance requirement, cost-effectiveness, and construction; whilst } \\
\text { PLA+ and bamboo slats have the least overall performance though } \\
\text { both have high advantage in terms of security requirement. }\end{array}$ \\
\hline
\end{tabular}

\section{Introduction}

Apart from building orientation (Prayoga, Budiyuwono, and Prajudi 2018), adaptive shading device is one of the most commonly used design strategies due to its ability to minimize the energy use by adapting to the weather that results in the increase of both thermal comfort and lighting quality inside a room (Aelenei et al. 2018; Yoon 2019; Al Dakheel and Tabet Aoul 2017). Number of studies evaluate these shadings performance have been done in regard to the indoor environment (Couvelas et al. 2018; Jayathis sa et al. 2017; Vailati et al. 2018). Adaptive shading also have its predecessor in a form of traditional blinds, that can also help reduce the energy consumption (Varun Sharma, Anuranjan Sharda, and Vijay Kumar 2016). These blinds have been gradually transformed into the adaptive ones (Barozzi et al. 2016). One of the typologies having the potential to be developed is Sliding Sudare (Hariyadi 2017). Previous research has initiated that the use of Sudare (a traditional Japanese shading device) gives the potential opportunities for energy savings within a building while still maintaining its visibility quality (Hariyadi and Hiroatsu 2017; Hariyadi, Fukuda, and $\mathrm{Ma}$ 2017). A conceptual model which displays the idea of a Sudare as a view regulator is provided in figure 1. 


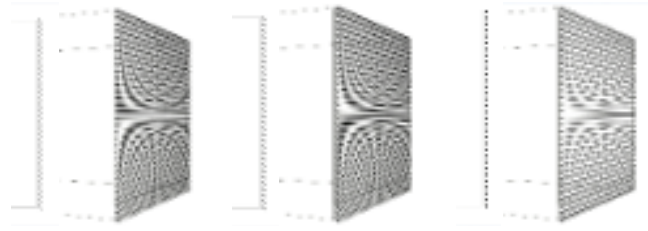

Figure 1. Sliding sudare conceptual model Source: (Hariy adi 2017)

The Sliding Sudare development is a response to climate change. Research by Hariyadi (2017) has investigated the use of a prototyping method concerning the working system of the adaptive shading device focusing on the automatic-kinetic system that performs a function of device panel driver to respond outside stimuli, in this context is outdoor illumination values. However, the original material of this shading device is bamboo that apparently cannot meet the Sliding Sudare blinds' requirements (narrow and thin). In that case, the material can be quickly damaged and cannot withstand exposure to the extreme weather. Due to its lack of development, this research aims to start an investigation regarding the potential material utilization for developing Sliding Sudare into an adaptive shading device systemthat meet the requirements desired

This material study holds an ess ential position in influencing the overall functional, structural, and detailed design of the device (Huang, Liu, and Liang 2015). Knowing that material selection is a crucial aspect of the shading device's working system, this research focuses on the exploration of probable materials to set out Sliding Sudare. The range of material is limited into three different types of material, that chosen due to its thinness and slimness.

\section{Method}

Some research has been done using either digital prototyping method (Tabadkani et al. 2019; Yoon and Bae 2020) or physical models equipped with an automatic-kinetic system. This research employed a method of Sliding Sudare automatickinetic system that have been formulated in the previous study (Hariyadi 2017). This prototyping process aims to measure the feasibility of, evaluate, and identify issues that might appear during the Sliding Sudare production, specifically concerning its material selection. The resulting prototypes will undergo an evaluation based on several parameters referring to Huang, Liu, and
Liang (2015)'s important aspects of material selection, namely (1) security requirement, (2) weather resistance, (3) construction, and (4) costeffectiveness. A more detailed explanation of these parameters is provided in the latter part of the manuscript.

Nevertheless, as previously mentioned, this research limits the material selection into three types of material with significant differences in their physical characteristics, such as stainless steel, plastic, and natural fiber. Considering the nature of such research based on a prototyping method, these materials was represented with three everyday objects namely bicycle spokes, $\mathrm{PLA}+(3 \mathrm{D}$ printer filament) and bamboo slats.

Preparation

On the frame production stage for stainless steel material, several potential is sues occur, for instance, a fine gap in the 3D printing results. This gap did not exist in the digital model and was unintentional due to the tolerance issue in the fabrication tool. Hence, several reprinting processes needed to be done until an appropriate tolerance setting was applied as in figure 2 . In addition, a number of models of reconstruction and reorientation processes were also carried out due to the limitation of the printing dimension of the $3 \mathrm{D}$ printer relative to the intended printing dimension of the digital model. During these reconstructions, the additional joint design was also created to accommodate the larger element printings.

Once the frame models are ready, the next process is to as semble the devices into frames that have been prepared. As mentioned previously, this assembly device is only applicable for stainless steeland bamboo slat materials, while an assembly of frames and devices for PLA+ material is performed on the digital modeling stage so it can be done simultaneously with the printing production. Illustration of the PLA+ made device is provided in figure 3 . 


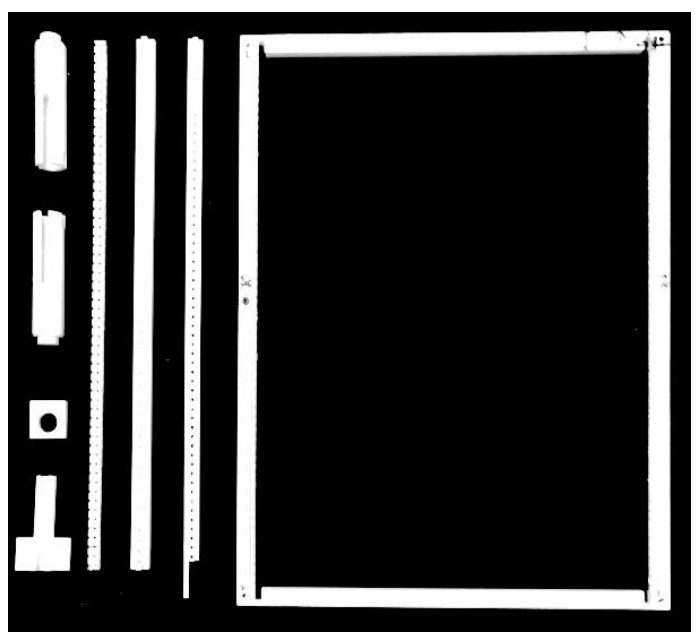

Figure 2. Parts of the frame

Prior to the assembly of stainless-steel devices, the material has to be prepared beforehand so it will result in the expected prototyping. In this context, a $150 \mathrm{~mm} \times 200 \mathrm{~mm}$ panel is required. Notwithstanding that the length of the available bicycle spokes is $1000 \mathrm{~mm}$, thus, an adjustment was done by cutting it into $150 \mathrm{~mm}$ using pliers. Illustration of the stainless-steel made device is provided in the following figure 4.

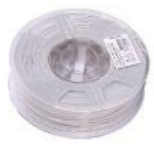

a.

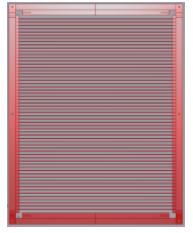

b.

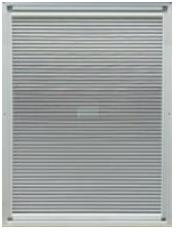

c.
Figure 3. a. Filament PLA+ material, b. Device and frame of digital 3D model, c. Frame and devices arrangement from PLA+ material

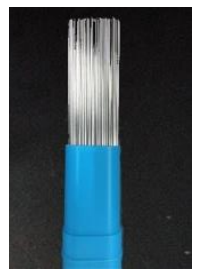

a.

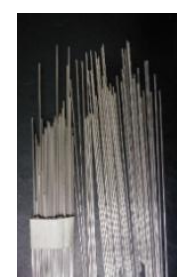

b.

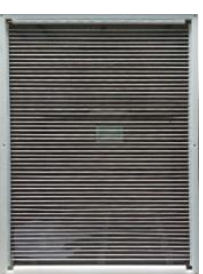

c.
Figure 4. a. Stainless steel material, b. Material cuts corresponding to frame dimensions, c. Frame and device assembly

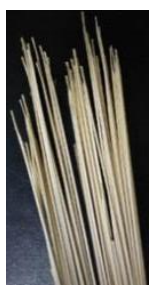

a

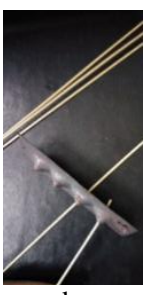

b

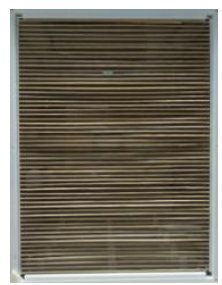

c
Figure 5. a. Bamboo material, b. Material cuts corresponding to frame dimensions, c. Frame and device assembly

The size adjusting process of the frame dimensions is also applicable to the horizontal blinds made of bamboo slats. A $1.5 \mathrm{~mm}$ diameter bamboo is the typical bamboo that is usually found in the marketplace, thus, it is necessary to adjust the diameter of the bamboo to stainless steel and 3D print filament's diameters. Furthermore, to create a device panel by means of bamboo slats, an important point to consider is the consistent diameter of each of the device elements. Size adjustment of the bamboo slats is done by scraping the diameter of the original bamboo into the desired diameter using a bamboo twisting machine. Illustration of the stainless -steel made device is provided in the following figure 5. Finally, the next step after the as sembly of device material and frames is to assemble the Sliding Device set into the system.

\section{Prototyping system}

Basically, all the processes involved in the aforementioned system takes place within a prototype setting in the form of a scaled physical model. Aside from the actual Sliding Sudare model, the prototype setting is also consisting of another model representing a room where the shading device would be installed and simulated in. This model developed in this research is based on the automatic-kinetic system and is also produced as a preparation to evaluate the visibility quality of the Sliding Sudare from inside and outside of the simulation room at a later stage of the research.

Thus, it is equipped with indoor illuminance sensors which are placed at certain points projecting every area in the room. It is essential to find out the illuminance value inside the room and map out the daylight distribution affected by the use of the shading device. Furthermore, a webcamera is set out to capture the situation inside the room on a heading of the outside room which is partitioned by the shading device. This setting 
aimed to record data on the visibility quality of the shading device from inside the simulation room. For the room model itself, the wall is built from 3 mm multiplex and the glass is made of $2.5 \mathrm{~mm}$ acrylic whilst the illuminance sensor's holder, servo motor's room, joint, roll, segment, and other supporting elements are made of 3D Print Filament material. Connected components are being assembled using right-sized bolts. Diagrams illustrating the prototyping scheme and setting are provided in figure 6 and figure 7 as follows.

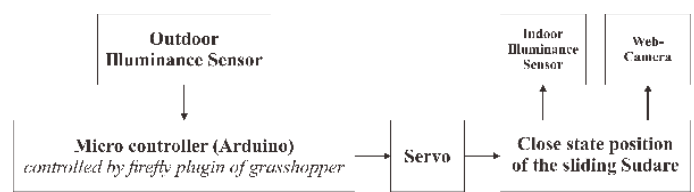

Figure 6. Sliding sudare prototy ping scheme

Then, as for the shading device itself, in principle, the device consists of three frames that move in synchronization in a certain way according to the automatic-kinetic system. The frames include front, center and back frame. The frame in the middle will directly be connected to the hasp that sticks on the wall. This frame will also become the basis of the other frames. Simply put, the central frame is static and has to be firmer than the others. Whilst, the back and front frames are dynamic in which the movement will adjust the outside condition. Consequently, it must be provided a space for a rope that connects the roll to the lever that is driven by the servo motor.

Furthermore, a pivotal principle of this prototyping process is to set the diameter of the device's horizontal blinds as small as possible within each frame in order to maximize the solid to void ratio of the device. This ratio is important in evaluating different visibility qualities of the room under different shading device arrangements and settings. The settings include a horizontal blind state of openness and material quality. However, in this context, the blind's diameter has been specified to be $1.2 \mathrm{~mm}$. This number is based on the standard measurement of bicycle spokes, as a representation of stainless steel material in this research.

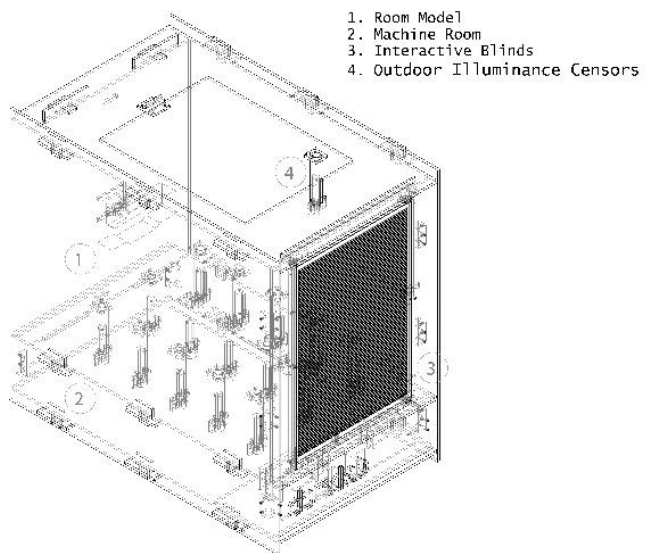

Figure 7. Detailed sliding sudare prototyping scheme

To install the device, perforated frames are prepared for stainless steel and bamboo materials. The size of the hole is adjusted to the diameter of the device material. Meanwhile, for Sliding Sudare with PLA+ material, the device is integrated with the frame so the process of producing both the frame and device can be done simultaneously. Those three frames are digitally designed parametrically by means of Grasshopper script in Rhinoceros modeling software and are produced using the PRUSA 3D printer. Diagram of detailed configuration for the frames are provided in figures 8 and 9 .

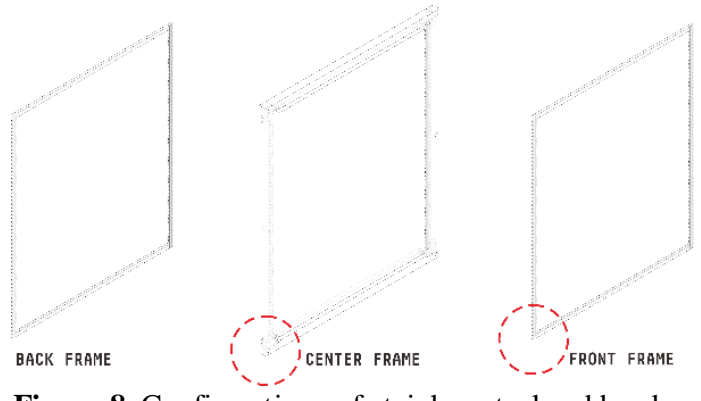

Figure 8. Configurations of stainless steel and bamboo frames

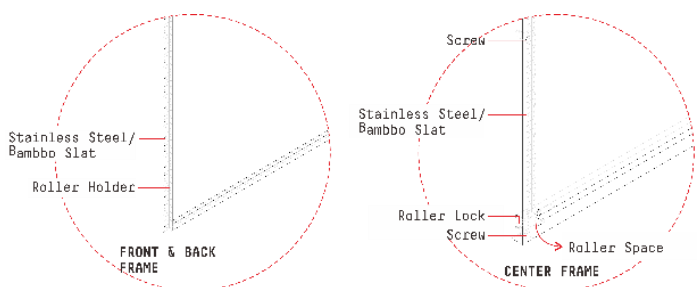

Figure 9. Detailed stainless steel and bamboo frames 


\section{Result and discussion}

Research findings

Several characteristics of the three materials based on the parameter evaluation and prototyping process are as follow:

\section{Bamboo materials}

The first material is bamboo slats (figure 10). Apart from its originality from Sudare and its massive use, bamboo slats also offer unique characteristics as mentioned in previous research that shading device made of bamboo performs a relatively similar quality as aluminum shading in terms of sunlight protection, considers sustainable, and much lower embodied energy during the production process (Caroline 2018).
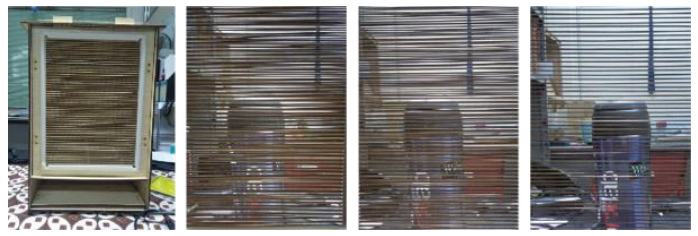

Figure 10. Prototy pe results using bamboo material

This natural material has a density of 0.31 $0.40 \mathrm{~kg} / \mathrm{dm} 3$ and is prone to the extreme weather. During hot weather, the water content in bamboo fibers potentially evaporates so that it can affect the diameter of the bamboo. On the contrary, the water content in bamboo fiber increases during humid days. This situation will most likely emerge fungi on the material surface.

Regarding the construction process, bamboo requires a quite long period of time in the fabrication process. Besides adjusting the size of this material to the dimension frame, the fabrication process on the stage of the frame assembly must be done by manual workers. Therefore, the precision and shape consistency levels rely heavily on the product-makers. Moreover, the device construction techniques takes longer time on the adjustment process of the size of the material and the dimension of both frames because their length and diameter need to be adjusted. Having said that, regarding to the expense, bamboo is a cheap and affordable material.

\section{Stainless Steel Materials}

The second material of choice is metal and represented with bicycle spokes (figure 11). Stainless steel is selected due to its complex characteristics, for instance, the astonishing corrosion resistance, excellent strength and great welding potency, lower thermal conductivity compared to other metals, and minimum thermal elongation due to heat (Hullmann and Willko mm 2009).
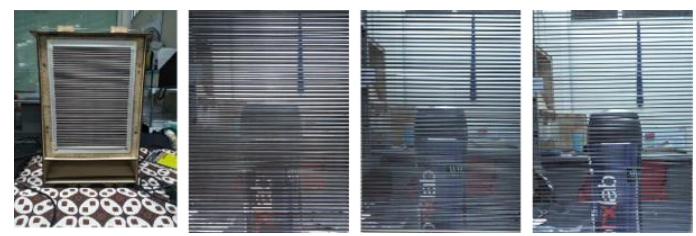

Figure 11. Prototy pe results using stainless steel

Stainless steel material has a density of 7.7 $8.0 \mathrm{~kg} / \mathrm{dm}^{3}$ and basically possesses excellent strength and weather resistance. In spite of that, it has a possibility to sag due to its small diameter $(1.2 \mathrm{~mm})$ and quite huge density. In regard to the model with a prototype's size that has been made, the strength of the device series using stainless steel material is still relatively safe and has no significant sag due to its quite short size, which is $150 \mathrm{~mm}$.

Regarding to the construction process, using stainless steel material requires a quite long period of time. Besides adjusting the size of stainless steel to the dimension frame, the fabrication process on the stage of the frame assembly must be done by manual workers. Therefore, the precision and shape consistency levels rely heavily on the product-makers. In addition, the motor load to drive the lever of the system is quite heavy in consequence of this material density. Moreover, the device construction techniques takes longer time on the adjustment process of the size of the material and the dimension of both frames because their length and diameter need to be adjusted. Furthermore, regarding to the expense, the raw material of stainless steel is quite expensive.

PLA+ 3D print filament materials

The second material is the 3D Print Filament (figure 12). This material is chosen because it is available in a large range of colours; thus, it opens up the possibility to produce colorful shading devices for supporting future investigations into the effect of colour selection on the devices' performance. This filament also offers extraordinary mechanical strength and processing potency, and a lot more promising prospects than 
other types of filaments such as ABS (Liu et al. 2017).
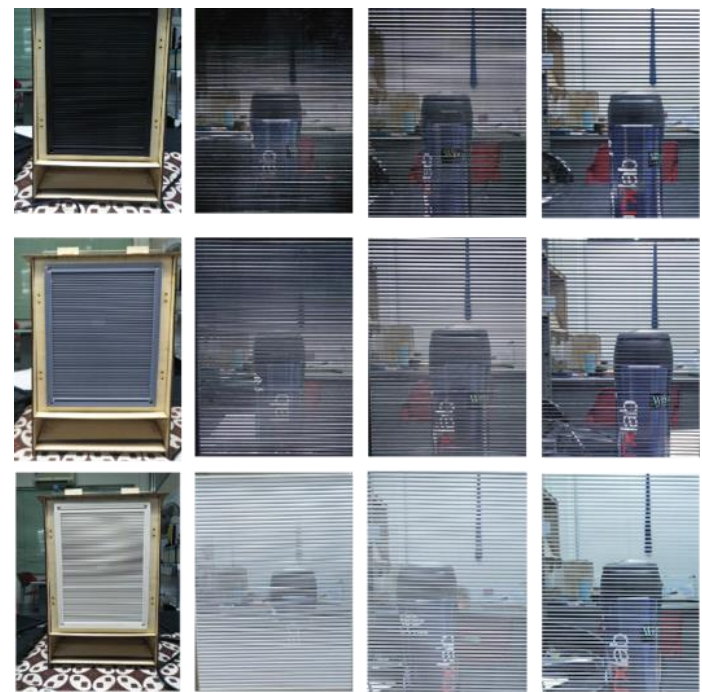

Figure 12. Prototype results with PLA+ 3D print filament in three different colors

This 3D Print Filament material has a density of $1.24 \mathrm{~kg} / \mathrm{dm}^{3}$ and quite light. At glance, this material performs better in terms of weather resistance. However, PLA+ is nonetheless a biodegradable synthetic material which can be broken due to sunlight.

Regarding to the construction process, the digital production by machines results in the uncomplicated PLA+ 3D Filament fabrication process and well-maintained precision and consistency levels. Moreover, the filaments are already available in various colors in a way that a color coating is not necessarily required. In addition, this material has an average-cost with regard to the expense.

To implement an adaptive shading device system into a building, several design stages require to be executed with regard to use's comfort, cost, and technical feasibility (Carletti, Sciurpi, and Pierangioli 2014). According to Huang, the number of design processes to set out the adaptive shading device include; determining the user's need, determining design specifications, selecting material, formulating the design regarding its function and construction, and fulfilling design stages in detail (Huang, Liu, and Liang 2015). Meanwhile, Romano (2018) classifies the readiness of the adaptive shading device into several categories, namely: (1) observed/reported basic principles/idea, (2) formulated technology concept/design, (3) proposal, (4) validated technology in the laboratory, (5) prototype demonstration, and (6) commercial product/existing building (Aelenei et al. 2018). A diagram explaining the stages set by Huang is presented in figure 13.

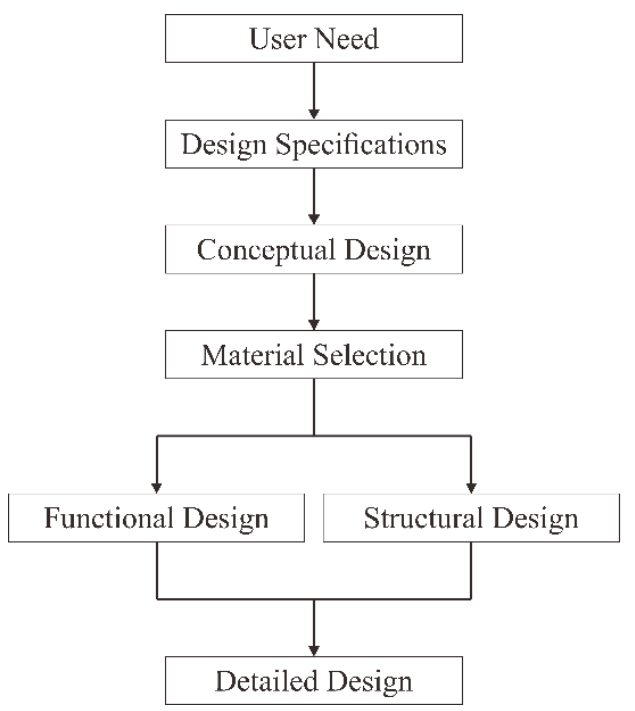

Figure 13. Design processes involved within the shading device

Source: (Huang, Liu, and Liang 2015)

This research focuses on Sliding Sudare's physical characteristics. Therefore, to evaluate that aspect, four parameters are set and the detailed explanation of the materials on each parameter is provided in the following paragraphs.

Weather resistance

Table 1. Data comparison of the materials durability

\begin{tabular}{ll}
\hline Mate rials & Durability \\
\hline Stainless Steel & 100 years \\
\hline PLA+3D Print Filament & 15 years \\
\hline Bamboo & 4 years \\
\hline
\end{tabular}

Bamboo as the original material of Sudare can only last 4 years of its total lifetime (Liese and Tang 2015). Regarding to the physical requirements such as thin and slim, this material may last faster than it supposed to be unless being coated with special coating. In contrast, stainless steel hold the record of 100 years for the raw material itself (Team Stainless, n.d.). This amount of years are later used as the benchmark for the other parameters. Whilst stainless steel has the longest lifespan, PLA+ has a 15 years lifespan 
which is considered as an average material time (3D Printer GEEKS 2019).

Security

Table 2. Data comparison of the materials density

\begin{tabular}{llll}
\hline Materials & $\begin{array}{l}\text { Density } \\
\text { (kg/dm3) }\end{array}$ & $\begin{array}{l}\text { Mass (gr } \\
\text { per unit) }\end{array}$ & $\begin{array}{l}\text { Unit Per } \\
\text { Servo Motor }\end{array}$ \\
\hline $\begin{array}{l}\text { Stainless } \\
\text { Steel }\end{array}$ & $7.7-8.0$ & 250 & 12 \\
\hline $\begin{array}{l}\text { PLA+3D } \\
\text { Print } \\
\text { Fillament }\end{array}$ & 1.24 & 100 & 30 \\
\hline Bamboo & $0.31-0.40$ & 75 & 40 \\
\hline
\end{tabular}

With the density as shown in the table, a whole Sudare consist of its frame and the blinds has increased dramatically on each material. Stainless steel has the highest mass value at $250 \mathrm{gr}$ per unit, whilst bamboo material has the lightest at $75 \mathrm{gr}$. The impact of this total mass affects the total amount of blinds which a servo can accommodate. By means of that, a lighter material which is bamboo can be held much more than the other material. With that advantage, the total amount of servo and energy used in the real building can be reduced to the minimum.

Cost- effectiveness

Table 3. Data comparison of the materials expense

\begin{tabular}{lll}
\hline Materials & $\begin{array}{l}\text { One-time } \\
\text { production (IDR) }\end{array}$ & $\begin{array}{l}\text { Per 100 years } \\
\text { production (IDR) }\end{array}$ \\
\hline $\begin{array}{l}\text { Stainless } \\
\text { Steel }\end{array}$ & 112.000 & 112.000 \\
\hline $\begin{array}{l}\text { PLA+3D } \\
\text { Print }\end{array}$ & 19.500 & 133.000 \\
Fillament & & \\
\hline Bamboo & 5.000 & 125.000 \\
\hline
\end{tabular}

Using the benchmark of 100 years combined with the durability of each material, the total production expense can be vary and different from the raw material cost. The cost of stainless steel that has 100 years lifespan itself remains constant, whilst the other material showing a significant difference and even cost more expensive. This rise is due to the constant replacement on the blinds material once the lifespan is over. For instance, each PLA+ and bamboo needs to be replaced at least 7 and 25 times during the years.

\section{Construction}

Table 4. Data comparison of the materials construction process

\begin{tabular}{llll}
\hline Materials & Phases & $\begin{array}{l}\text { Production } \\
\text { Time (hrs) }\end{array}$ & $\begin{array}{l}\text { Production } \\
\text { Time Per 100 } \\
\text { years (hrs) }\end{array}$ \\
\hline $\begin{array}{l}\text { Stainless } \\
\text { Steel }\end{array}$ & 2 & 9 & 9 \\
\hline $\begin{array}{l}\text { PLA+3D } \\
\begin{array}{l}\text { Print } \\
\text { Fillament }\end{array}\end{array}$ & 2 & 14 & 98 \\
\hline Bamboo & 3 & 11 & 275 \\
\hline
\end{tabular}

Each material has different phases on regards to the construction process. The more phases a material requires, the more production time it demands. Not to mention, the energy used on the material replacement is also affected. Taking the example of bamboo that has 3 phases and the requirements of constant replacement takes 275 hours, which is way longer than stainless steel that does not need any changing within the years.

The result of this cross-comparison in scoring format is provided in table 5. The amount of the numeric score indicates the superiority of one material to others.

Table 5. Scoring on the cross-comparison of the materials

\begin{tabular}{lccccc}
\hline Mate rial & \multicolumn{4}{c}{ Score per Parameter } & Total \\
\cline { 2 - 5 } & $\begin{array}{l}\text { Weather } \\
\text { Resistance }\end{array}$ & Security Cost & Construction & Score \\
\hline $\begin{array}{l}\text { Stainless } \\
\text { Steel }\end{array}$ & 3 & 1 & 3 & 3 & 10 \\
\hline $\begin{array}{l}\text { PLA+ 3D } \\
\text { Filament }\end{array}$ & 2 & 2 & 1 & 2 & 7 \\
\hline $\begin{array}{l}\text { Bamboo } \\
\text { Slat }\end{array}$ & 1 & 3 & 2 & 1 & 7 \\
\hline
\end{tabular}

Legend: 1: Poor, 2: Good, 3: Excellent

\section{Conclusion}

Bamboo slats, PLA+ 3D Print Filament, and bicycle spokes were tested as Sliding Sudare alternative materials. Four parameters were used to evaluate those materials using prototyping method. Based on the analysis and discussion, it can be concluded that bicycle spokes has the highest overall performance with the highest advantages in weather resistance requirement, cost-effectiveness, and construction; whilst PLA+ and bamboo slats have the least overall performance though both have high advantage in terms of security requirement. 
Following this initial material-focused research, a deeper analysis concerning the type of metal that can be lighter with a long lifespan needs to be done. The evaluation of this next study could be done by utilizing the physical prototyping setting that has been developed in this research. Moreover, a bigger scaled model or a full-scale model corresponding to the size of windows is suggested to be developed to evaluate the working performance of the system and to justify the potential is sue of the real-size model.

\section{References}

3D Printer GEEKS. 2019. 'How Long Will a PLA 3D Printed Object Last?' Guides/PLA. 2019. https://3dprintergeeks.com/pla-3d-printedobject-durability/\#: :text=The environmental humidity $\% 2 \mathrm{C}$ rainy weather,with the presence of microorganis ms.

Aelenei, Laura, Daniel Aelenei, Rosa Romano, Enrico Sergio Mazzucchelli, Marcin Brzezicki, and Jose Miguel Rico-Martinez, eds. 2018. Case Studies-Adaptive Facade Network. TU Delft Open. https://core.ac.uk/download/pdf/186456109.p df.

Barozzi, Marta, Julian Lienhard, Alessandra Zanelli, and Carol Monticelli. 2016. 'The Sustainability of Adaptive Envelopes: Developments of Kinetic Architecture'. Procedia Engineering 155: 275-84. https://doi.org/10.1016/j.proeng.2016.08.029.

Carletti, Cristina, Fabio Sciurpi, and Leone Pierangioli. 2014. 'The Energy Upgrading of Existing Buildings: Window and Shading Device Typologies for Energy Efficiency Refurbishment'. Sustainability 6 (8): 535477. https://doi.org/10.3390/su6085354.

Caroline, Octaviana Sylvia. 2018. 'Implementing Bamboo Research into Holistic Architecture Design for Creating Thermally Comfortable Interior Environment in Gili Meno, Indonesia'. IOP Conference Series: Earth and Environmental Science 195 (December): 012089. https://doi.org/10.1088/17551315/195/1/012089.

Couvelas, Agnes, Marios Phocas, Feray Maden, Maria Matheou, and Duhan Ölmez. 2018. 'Daylight Performance of an Adaptive Façade Shading System Integrated on a Multi-Storey Office Building'. In 13th Conference on
Advanced Building Skins, 423-32. Bern, Switzwerland: ABS. https://gnosis .library.ucy.ac.cy/handle/7/6185 2.

Dakheel, Joud Al, and Kheira Tabet Aoul. 2017. 'Building Applications, Opportunities and Challenges of Active Shading Systems: A State-of-the-Art Review'. Energies 10 (10): 1672. https://doi.org/10.3390/en 10101672.

Hariyadi, Agus.2017. 'Study on Optimization of Visibility and Energy Efficiency of New “Sudare” for Building Façade 利用統計を見 る '. The University of Kitakyushu. https ://kitakyu.repo.nii.ac.jp/?action=pages_v iew_main\&active_action=repository_view_ main_item_detail\&item_id $=595 \&$ ite $m \_n o=1$ \&page_id=13\&block_id=294.

Hariyadi, Agus, Hiroatsu Fukuda, and Qingsong Ma. 2017. 'The Effectiveness of the Parametric Design "Sudare" Blind as External Shading for Energy Efficiency and Visibility Quality in Jakarta'. Architectural Engineering and Design Management 13 (5): 384-403. https://doi.org/10.1080/17452007.2017.1296 811.

Hariyadi, Agus, and Fukuda Hiroatsu. 2017. 'Study of Visibility Indices of Traditional Japanese Horizontal Blind " Sudare " Based on the Illuminance Different Level Using Physical and Digital Image Experiment'. BUILT-International Journal of Building, Urban, Interior and Landscape Technology 9: 15-24. https://repository.ugm.ac.id/274045/.

Huang, Kuo-Tsang, Kevin Liu, and Han-Hsi Liang. 2015. 'Design and Energy Performance of a Buoyancy Driven Exterior Shading Device for Building Application in Taiwan'. Energies 8 (4): 2358-80. https://doi.org/10.3390/en8042358.

Hullmann, Heinz, and Wolfgang Willkomm. 2009. 'Stainless Steel and Solar Energy in Building Applications'. Belgium. https://www.worldstainless s.org/Files/is sf/non -imagefiles/PDF/ISSF_Stainless_Steel_and_Solar_E nergy_in_Building_Applications.pdf.

Jayathis sa, P., M. Luzzatto, J. Schmidli, J. Hofer, Z. Nagy, and A. Schlueter. 2017. 'Optimising Building Net Energy Demand with Dynamic BIPV Shading'. Applied Energy 202 (September): $\quad$ 726-35. 
https://doi.org/10.1016/j.apenergy.2017.05.0 83.

Liese, Walter, and Thi Kim Hong Tang. 2015. 'Preservation and Drying of Bamboo'. In , 257-97. https://doi.org/10.1007/978-3-31914133-6_9.

Liu, Wenjie, Jianping Zhou, Yuming Ma, Jie Wang, and Jie Xu. 2017. 'Fabrication of PLA Filaments and Its Printable Performance'. IOP Conference Series: Materials Science and Engineering 275 (December): 012033. https://doi.org/10.1088/1757899X/275/1/012033.

Prayoga, Mochammad Ardi, Hartanto Budiyuwono, and Rahadian Prajudi. 2018. 'Tata Ruang Dalam Rumah Sederhana Tipe 54 Perumahan Kedung Badak Baru Bogor Ditinjau Dari Pencahayaan'. ARTEKS : Jurnal Teknik Arsitektur 2 (2): 137-48. https://doi.org/10.30822/arteks.v2i1.47.

Tabadkani, Amir, Masoud Valinejad Shoubi, Farzaneh Soflaei, and Saeed Banihashemi. 2019. 'Integrated Parametric Design of Adaptive Facades for User's Visual Comfort'. Automation in Construction 106 (October): 102857. https://doi.org/10.1016/j.autcon.2019.102857

Team Stainless. n.d. 'Stainless Steel for a Sustainable https://www.worldstainles s.org/Files/ISSF/no n-image-

files/PDF/Team_Stainless_Stainless_Steel_fo r_a_Sustainable_Future.pdf.

Vailati, C., E. Bachtiar, P. Hass, I. Burgert, and M. Rüggeberg. 2018. 'An Autonomous Shading System Based on Coupled Wood Bilayer Elements'. Energy and Buildings 158 (January):

1013-22. https://doi.org/10.1016/j.enbuild.2017.10.042

Varun Sharma, Anuranjan Sharda, and Vijay Kumar. 2016. 'Simulation Thermal Analysis of Double Glazed Window with Interpane Chik Blind'. International Journal of Engineering Research And V5 (07). https://doi.org/10.17577/IJERTV5IS070083.

Yoon, Jungwon. 2019. 'SMP Prototype Design and Fabrication for Thermo-Responsive Façade Elements'. Journal of Facade Design and Engineering 7 (1): 41-62. https://doi.org/https://doi.org/10.7480/jfde.20 19.1.2662.

Yoon, Jungwon, and Sanghyun Bae. 2020. 'Performance Evaluation and Design of Thermo-Responsive SMP Shading Prototypes'. Sustainability 12 (11): 4391. https://doi.org/10.3390/su12114391. 
ARTEKS : Jurnal Teknik Arsitektur, Volume 6 Issue 1, April 2021

pISSN2541-0598; eISSN2541-1217 